\title{
The occurrence of coronary artery lesions in Kawasaki disease based on C-reactive protein levels: a retrospective cohort study
}

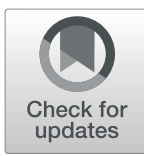

Hyo Soon An, Gi Beom Kim (D), Mi Kyoung Song, Sang Yun Lee, Hye Won Kwon, Joo Won Lee and Eun Jung Bae

\begin{abstract}
Background: This study aimed to assess the occurrence of coronary artery lesions (CAL) in patients with Kawasaki disease (KD) according to serum C-reactive protein (CRP) levels.

Methods: This retrospective analysis was based on the nationwide survey of KD conducted in the Republic of Korea between 2015 and 2017. We enrolled 9131 patients and defined low $(<3 \mathrm{mg} / \mathrm{dL})$ and high ( $\geq 3 \mathrm{mg} / \mathrm{dL}) \mathrm{CRP}$ groups. Demographic data, clinical characteristics, z-scores, and scores based on the Japanese criteria for CAL were compared between the two groups. Logistic regression analysis was used to identify CAL risk factors.

Results: The low CRP group accounted for $23 \%$ of patients. The mean age at diagnosis was higher in high CRP group compared to the low CRP group ( $34.4 \pm 24.9$ vs $31.7 \pm 24.8$ months, $p<0.001)$. Fever duration before treatment was not significantly different between the two groups ( $5.1 \pm 1.7$ days vs. $5.2 \pm 2.1$ days; $p=0.206$ ). A nonresponse to intravenous immunoglobulin treatment was found in 1377 patients (20.1\%) and 225 patients (11.7\%) in the high and low CRP groups, respectively $(p<0.001)$. CAL were found in 12.9 and $18.3 \%$ of the high and low CRP patients, respectively $(p<0.001)$, based on $z$-scores; and in 9.9 and $12.5 \%$, respectively $(p=0.001)$, based on the Japanese criteria in the acute phase. The giant coronary artery aneurysm occurrence ratio was similar between groups $(p=1.0)$.
\end{abstract}

Conclusions: CAL occurred in patients with both high and low CRP. Therefore, patients with KD should be carefully monitored regardless of their CRP levels.

Keywords: Acute-phase reactants, Coronary aneurysm, Intravenous immunoglobulins, Mucocutaneous lymph node syndrome, Risk factors

\section{Background}

Kawasaki disease (KD) is a systemic inflammatory vascular disease that results in coronary artery complications in $25 \%$ of untreated patients [1]. This disease is reported in high frequency, particularly in Northeast Asia, including Korea, and occurs primarily in children under 5 years of age [2]. Systemic inflammation in KD is reflected by

\footnotetext{
* Correspondence: ped9526@snu.ac.kr

Department of Pediatrics, Seoul National University Children's Hospital, Seoul National University College of Medicine, 101 Daehak-ro, Jongno-gu, Seoul 03080, South Korea
}

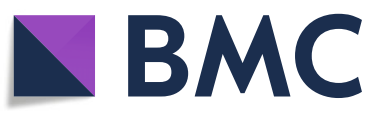

an elevation of serum C-reactive protein (CRP) levels, an acute phase reactant. In general, high serum CRP levels are expected in KD. Therefore, in patients presenting with incomplete $\mathrm{KD}$ that does not fulfill the diagnostic criteria, a CRP serum level $>3 \mathrm{mg} / \mathrm{dL}$ is used as a criterion to confirm KD [1].

At the same time, this rise in serum CRP levels is also used as an index to predict KD that is refractory to treatment [3-5]. Since the main purpose of KD treatment is to minimize the occurrence of coronary artery complications through appropriate treatment, patients with high

(c) The Author(s). 2021 Open Access This article is licensed under a Creative Commons Attribution 4.0 International License, which permits use, sharing, adaptation, distribution and reproduction in any medium or format, as long as you give appropriate credit to the original author(s) and the source, provide a link to the Creative Commons licence, and indicate if changes were made. The images or other third party material in this article are included in the article's Creative Commons licence, unless indicated otherwise in a credit line to the material. If material is not included in the article's Creative Commons licence and your intended use is not permitted by statutory regulation or exceeds the permitted use, you will need to obtain permission directly from the copyright holder. To view a copy of this licence, visit http://creativecommons.org/licenses/by/4.0/ The Creative Commons Public Domain Dedication waiver (http://creativecommons.org/publicdomain/zero/1.0/) applies to the data made available in this article, unless otherwise stated in a credit line to the data. 
CRP, which are expected to be less responsive to treatment, are treated with caution. However, in clinical practice, coronary artery complications are often seen even in KD patients with low CRP levels. In this study, we aimed to assess the clinical features and occurrence of coronary artery lesions (CAL) in patients with KD according to serum CRP levels. In addition, we tried to confirm whether CAL occurred in patients with low serum CRP level before IVIG treatment.

\section{Methods}

This study was based on the 9th nationwide KD survey performed under the guidance of the Korean Society of KD in the Republic of Korea, which was conducted on patients with KD who visited a hospital between January 2015 and December 2017. Data were collected using a questionnaire regarding the clinical characteristics of patients, which were filled in by hospital medical staff. The survey was approved by the Institutional Review Board of our university hospital (no. H-1710-109-895, approved November 20, 2017).

The survey obtained data from 15,387 patients. Of these patients, 6256 were excluded due to missing data on serum CRP levels, coronary artery size, height, and weight. Eventually, 9131 patients were enrolled in the study and were divided into two groups according to their serum CRP levels: low $(<3 \mathrm{mg} / \mathrm{dL})$ and high $(\geq 3$ $\mathrm{mg} / \mathrm{dL}$ ). We recorded serum CRP levels just before the start of acute treatment. Coronary artery evaluation was performed with echocardiography twice, during the acute phase (maximal dilatation of the coronary arteries after intravenous immunoglobulin [IVIG] treatment; $n=9014$ ) and post-convalescent period (approximately 8 weeks after disease onset; $n=8206$ ).

The diagnosis of complete KD was based on the presence of four or more of the principal clinical criteria (extremity changes, rash, conjunctivitis, oral changes, cervical lymphadenopathy), and patients with three or fewer criteria and compatible laboratory or echocardiographic findings were considered to have incomplete KD [1]. Non-responsiveness to initial IVIG treatment was defined as the requirement for the administration of second-line treatment, such as a second dose of IVIG or intravenous steroids.

The complications of KD were assessed based on the development of CAL on the left main coronary artery. The z-score was calculated using a previously reported formula [6], and a $\mathrm{z}$-score $\geq 2.5$ was considered to be CAL. We also assessed CAL development according to the criteria of the Japanese Ministry of Health and Welfare (Japanese criteria) [7, 8], which defined CAL as a coronary artery diameter $\geq 3 \mathrm{~mm}$ in children $<5$ years old and $\geq 4 \mathrm{~mm}$ in children $\geq 5$ years old. A $\mathrm{z}$-score $\geq 10.0$ and diameter $>8 \mathrm{~mm}$ were considered to indicate a giant coronary artery aneurysm (CAA).

\section{Statistical analysis}

Data were expressed as the mean \pm standard deviation, median (range), or percentage (\%), as appropriate. We compared the characteristics of patients, treatment, and coronary artery complications between the low and high CRP groups. An independent t-test was performed to compare continuous variables, and a chi-squared test was used to analyze categorical variables. We performed logistic regression analysis to identify potential risk factors for the development of CAL. A $p$-value $<0.05$ was considered statistically significant. All statistical analyses were conducted using IBM SPSS Statistics for Windows, version 20 (IBM Corp., Armonk, NY, USA).

\section{Results}

The mean age at diagnosis was $33.7 \pm 24.9$ months, and the proportion of male children was $58.1 \%$ (male:female ratio, 1.41:1). The average duration of fever before treatment was $5.1 \pm 1.8$ days, and the total fever duration was $6.5 \pm 2.3$ days. The mean serum CRP level in all children was $7.4 \pm 5.8 \mathrm{mg} / \mathrm{dL}$. The low CRP group accounted for $23 \%$ of all KD patients.

\section{Comparison of clinical characteristics by CRP level}

The mean age at diagnosis was higher in the high CRP group compared to the low CRP group (34.4 \pm 24.9 vs $31.7 \pm 24.8$ months, $p<0.001)$ and total fever duration was longer in the high CRP group than the low CRP group $(6.6 \pm 2.2$ vs $6.3 \pm 2.5$ days, $p<0.001)$. However, pretreatment fever duration was not significantly different between the two groups (high vs. low group, $5.1 \pm$ 1.7 days vs. $5.2 \pm 2.1$ days; $p=0.206$ ). The principal symptoms, except for Bacillus Calmette-Guérin (BCG) site redness, were all more frequently observed in the high CRP group than in the low CRP group. An incomplete presentation of KD was more frequently observed in the low CRP group than in the high CRP group (high vs. low group, $31.7 \%$ vs. $42.1 \%, p<0.001)$. White blood cell count, percentage of neutrophil count, aspartate aminotransferase, and alanine aminotransferase levels were significantly higher in the high CRP group than in the low CRP group (Table 1).

\section{Treatment of KD}

Overall, 341 (3.7\%) patients were not given IVIG because of spontaneous alleviation of fever. Such patients were found more frequently in the low CRP group than in the high CRP group (low vs. high groups, 174 (8.3\%) patients vs. $167(2.4 \%)$ patients; $p<0.001)$. The first-line drug treatment for acute KD was IVIG $(2 \mathrm{~g} / \mathrm{kg}$ ), and $1602 \mathrm{pa}-$ tients were non-responsive to this treatment (18.3\%). 
Table 1 Clinical characteristics between patients with low and high C-reactive protein levels among patient with KD

\begin{tabular}{|c|c|c|c|c|c|c|}
\hline \multirow[t]{2}{*}{ Characteristics } & \multirow[t]{2}{*}{ Total } & \multicolumn{2}{|c|}{ Low CRP $<3 \mathrm{mg} / \mathrm{dL}$} & \multicolumn{2}{|c|}{ High $C R P \geq 3 \mathrm{mg} / \mathrm{dL}$} & \multirow{2}{*}{$\begin{array}{l}p \text { - } \\
\text { value }\end{array}$} \\
\hline & & $\mathrm{n}$ & Value & $\mathrm{n}$ & Value & \\
\hline N (\%) & 9131 & 2107 & 23.1 & 7024 & 76.9 & \\
\hline Age, months (mean $\pm S D$ ) & 9131 & 2107 & $31.7 \pm 24.8$ & 7024 & $34.4 \pm 24.9$ & $<0.001$ \\
\hline Male, n (\%) & 9053 & 2081 & $1261(60.6)$ & 6972 & $4042(58.0)$ & 0.033 \\
\hline Weight, kg (mean \pm SD) & 9131 & 2107 & $13.8 \pm 6.0$ & 7024 & $14.2 \pm 5.9$ & 0.003 \\
\hline Height, $\mathrm{cm}$ (mean $\pm \mathrm{SD})$ & 9131 & 2107 & $90.2 \pm 17.4$ & 7024 & $92.2 \pm 17.3$ & $<0.001$ \\
\hline Fever, total days (mean \pm SD) & 8810 & 2027 & $6.3 \pm 2.5$ & 6783 & $6.6 \pm 2.2$ & $<0.001$ \\
\hline Fever, pretreatment, days (mean $\pm \mathrm{SD}$ ) & 9025 & 2072 & $5.2 \pm 2.1$ & 6998 & $5.1 \pm 1.7$ & 0.206 \\
\hline \multicolumn{7}{|l|}{ Symptoms, n (\%) } \\
\hline Conjunctival injection & 9010 & 2054 & $1664(81.0)$ & 6956 & $6220(89.4)$ & $<0.001$ \\
\hline Oral changes & 9001 & 2050 & $1604(78.2)$ & 6951 & $5865(84.4)$ & $<0.001$ \\
\hline Extremity changes & 8918 & 2028 & $1247(61.5)$ & 6890 & $4651(67.5)$ & $<0.001$ \\
\hline Rash & 8984 & 2053 & $1484(72.3)$ & 6931 & $5349(77.2)$ & $<0.001$ \\
\hline BCG site redness & 8354 & 1914 & $769(40.2)$ & 6440 & $2520(39.1)$ & 0.424 \\
\hline Cervical lymphadenopathy & 8960 & 2047 & 1015 (49.6) & 6913 & $4179(60.5)$ & $<0.001$ \\
\hline Incomplete presentation, n (\%) & 8914 & 2006 & $844(42.1)$ & 6908 & $2187(31.7)$ & $<0.001$ \\
\hline Family history, n (\%) & 6543 & 1414 & $24(1.7)$ & 5129 & $68(1.3)$ & 0.312 \\
\hline Recurrence, n (\%) & 8781 & 2017 & $99(4.9)$ & 6763 & $337(5.0)$ & 0.953 \\
\hline \multicolumn{7}{|l|}{ Laboratory results } \\
\hline $\mathrm{WBC}, / \mathrm{mm}^{3}($ mean $\pm \mathrm{SD})$ & 9126 & 2106 & $11.988 \pm 4.881$ & 7020 & $14.818 \pm 5.163$ & $<0.001$ \\
\hline Neutrophil, \% (mean \pm SD) & 9037 & 2066 & $52.2 \pm 16.9$ & 6971 & $66.5 \pm 14.6$ & $<0.001$ \\
\hline Hemoglobin, g/dL (mean \pm SD) & 9096 & 2100 & $11.6 \pm 0.97$ & 6996 & $11.3 \pm 1.02$ & $<0.001$ \\
\hline Platelets, $\times 10^{3}($ mean \pm SD $)$ & 9105 & 2103 & $357.4 \pm 126.8$ & 7002 & $356.5 \pm 109.8$ & 0.765 \\
\hline Platelets, $\times 10[3]$, highest (mean \pm SD) & 8651 & 2002 & $422.6 \pm 147.0$ & 6649 & $483.6 \pm 165.4$ & $<0.001$ \\
\hline Albumin, g/dL (mean \pm SD) & 9093 & 2093 & $4.0 \pm 0.3$ & 7000 & $3.8 \pm 0.4$ & $<0.001$ \\
\hline AST, IU/L (mean $\pm S D)$ & 9105 & 2100 & $64.6 \pm 125.9$ & 7005 & $94.0 \pm 173.5$ & $<0.001$ \\
\hline $\mathrm{ALT}, \mathrm{IU} / \mathrm{L}($ mean $\pm \mathrm{SD})$ & 9095 & 2096 & $59.8 \pm 131.5$ & 6999 & $100.1 \pm 149.3$ & $<0.001$ \\
\hline Total bilirubin, mg/dL (mean \pm SD) & 8978 & 2070 & $0.4 \pm 0.47$ & 6908 & $0.68 \pm 0.83$ & $<0.001$ \\
\hline $\mathrm{Na}, \mathrm{mEq} / \mathrm{L}($ mean $\pm \mathrm{SD})$ & 8983 & 2059 & $137.0 \pm 2.4$ & 6924 & $136.2 \pm 2.7$ & $<0.001$ \\
\hline $\mathrm{CRP}, \mathrm{mg} / \mathrm{dL}($ mean $\pm \mathrm{SD})$ & 9131 & 2107 & $1.59 \pm 0.86$ & 7024 & $9.20 \pm 5.49$ & $<0.001$ \\
\hline ESR, mm/hr. (mean \pm SD) & 8356 & 1919 & $41.5 \pm 24.9$ & 6437 & $60.7 \pm 26.7$ & $<0.001$ \\
\hline BNP, pg/mL (mean $\pm S D)$ & 2079 & 519 & $55.3 \pm 94.0$ & 1559 & $199.4 \pm 597.3$ & $<0.001$ \\
\hline ProBNP, pg/mL (mean \pm SD) & 5533 & 1266 & $551.5 \pm 1081.5$ & 4267 & $1624.2 \pm 3400.8$ & $<0.001$ \\
\hline Pyuria, n (\%) & 9008 & 2076 & 409 (19.7) & 6932 & $2652(38.3)$ & $<0.001$ \\
\hline
\end{tabular}

$K D$ Kawasaki Disease, CRP C-reactive protein, BCG Bacillus Calmette-Guérin, WBC White blood cell, AST Aspartate aminotransferase, ALT Alanine aminotransferase, $B N P$ B-type natriuretic peptide, SD Standard deviation

The non-response rate was lower in the low CRP group than in the high CRP group (225 [11.7\%] patients vs. 1377 [20.1\%] patients, respectively; $p<0.001)$. Among patients who were non-responsive to initial IVIG, a second IVIG dose was administered to 1435 patients (89.6\%). Among them, 342 patients were non-responsive (23.8\%), and there was no significant difference between the two groups (high vs. low group, 302 [24.4\%] patients vs. 40 [20.2\%] patients; $p=0.209$; Table 2).

\section{Coronary artery complications}

In the acute phase, the overall prevalence of CAL was $14.1 \%$ based on the $\mathrm{z}$-score and $10.5 \%$ based on the Japanese criteria. After the convalescent period, the CAL prevalence, according to the two criteria, decreased to 6.1 and $5.1 \%$, respectively. A giant CAA was found in $0.6 \%$ (z-score) and $0.1 \%$ (Japanese criteria) of patients in the acute phase and $0.3 \%(\mathrm{z}$-score) and $0.1 \%$ (Japanese criteria) after the convalescent period (Fig. 1). A decline 
Table 2 Response to treatment and coronary artery complications in children with Kawasaki disease

\begin{tabular}{|c|c|c|c|c|c|c|}
\hline \multirow{2}{*}{$\begin{array}{l}\text { Outcomes } \\
\text { Spontaneous remission }\end{array}$} & \multirow{2}{*}{$\begin{array}{l}\begin{array}{l}\text { Total } \\
\text { n (\%) }\end{array} \\
341(3.7)\end{array}$} & \multicolumn{2}{|c|}{$\begin{array}{l}\text { Low CRP }<3 \mathrm{mg} / \mathrm{dL} \\
(n=2107), \mathrm{n}(\%)\end{array}$} & \multicolumn{2}{|c|}{$\begin{array}{l}\text { High CRP } \geq 3 \mathrm{mg} / \mathrm{dL} \\
(n=7024), \mathrm{n}(\%)\end{array}$} & \multirow{2}{*}{$\begin{array}{c}\boldsymbol{p} \text {-value } \\
<0.001\end{array}$} \\
\hline & & & $174(8.3)$ & & $167(2.4)$ & \\
\hline 1st IVIG & $8778(96.1)$ & & $1929(91.6)$ & & $6849(97.5)$ & $<0.001$ \\
\hline Unresponsive to $1 \mathrm{st}$ IVIG & $1602 / 8778(18.3)$ & & $225(11.7)$ & & $1377(20.1)$ & $<0.001$ \\
\hline 2nd IVIG & 1435/1602 (89.6) & & $198(88.0)$ & & $1237(89.8)$ & 0.453 \\
\hline Unresponsive to 2nd IVIG & $342 / 1435(23.8)$ & & $40(20.2)$ & & $302(24.4)$ & 0.209 \\
\hline \multicolumn{7}{|l|}{ Acute CAL } \\
\hline$z$-score & $1271 / 9000(14.1)$ & 2082 & $380(18.3)$ & 6918 & $891(12.9)$ & $<0.001$ \\
\hline Japanese criteria & $946 / 9014(10.5)$ & 2084 & $260(12.5)$ & 6930 & $686(9.9)$ & 0.001 \\
\hline \multicolumn{7}{|l|}{ Acute giant CAA } \\
\hline z-score & $56 / 9014(0.6)$ & 2084 & $13(0.6)$ & 6930 & $43(0.6)$ & 1.0 \\
\hline Japanese criteria & $13 / 9110(0.1)$ & 2101 & $3(0.1)$ & 7009 & $10(0.1)$ & 1.0 \\
\hline \multicolumn{7}{|l|}{ Convalescent CAL } \\
\hline z-score & $501 / 8196(6.1)$ & 1873 & $160(8.5)$ & 6323 & $341(5.4)$ & $<0.001$ \\
\hline Japanese criteria & 419/8203 (5.1) & 1875 & $127(6.8)$ & 6328 & $292(4.6)$ & $<0.001$ \\
\hline \multicolumn{7}{|l|}{ Convalescent giant CAA } \\
\hline z-score & 28/8204 (0.3) & 1875 & $1(0.1)$ & 6329 & $27(0.4)$ & 0.011 \\
\hline Japanese criteria & $8 / 8661(0.1)$ & 1971 & 0 & 6690 & $8(0.1)$ & 0.212 \\
\hline
\end{tabular}

KD Kawasaki Disease, CRP C-reactive protein, IVIG Intravenous immunoglobulin treatment, CAL Coronary artery lesion, CAA Coronary artery aneurysm; Japanese criteria, criteria of the Japanese Ministry of Ministry of Health and Welfare

in both the size and prevalence of CAL was found in the post-convalescent period compared to the acute phase of KD based on both criteria (z-score and Japanese criteria; Fig. 2).

In this study, the occurrence of CAL was higher in incomplete KD than complete KD. (Supplementary 3), and these incomplete KD was higher in the low CRP group. In the other hand, in an analysis performed only in incomplete KD patients, the occurrence of CAL was frequent in low CRP group than the high CRP group. However in complete KD patients, there was not difference of CAL by CRP group. (Supplementary Table 4A, B).

Fever duration before treatment was one of the risk factors for the development of acute CAL in the

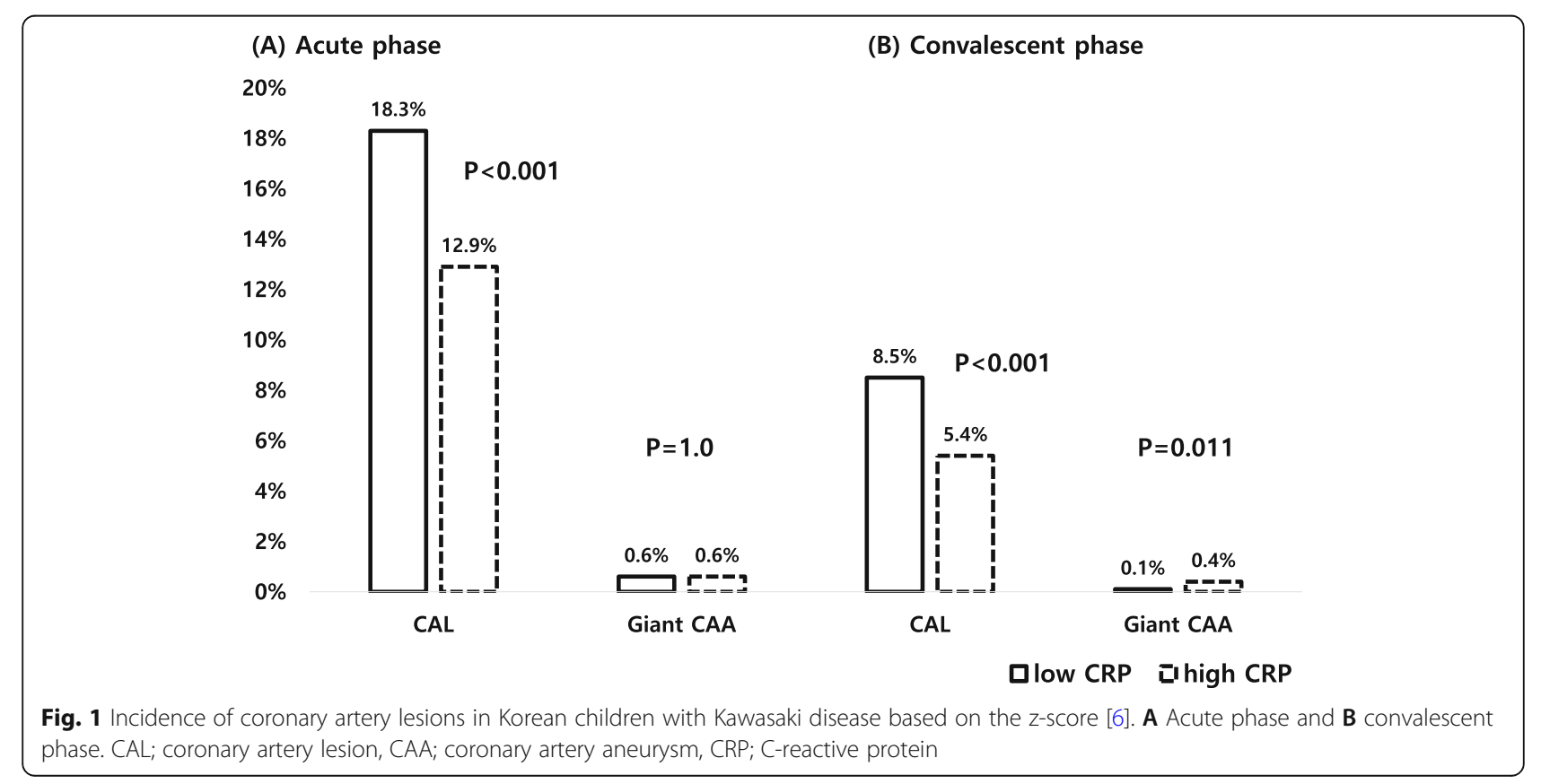




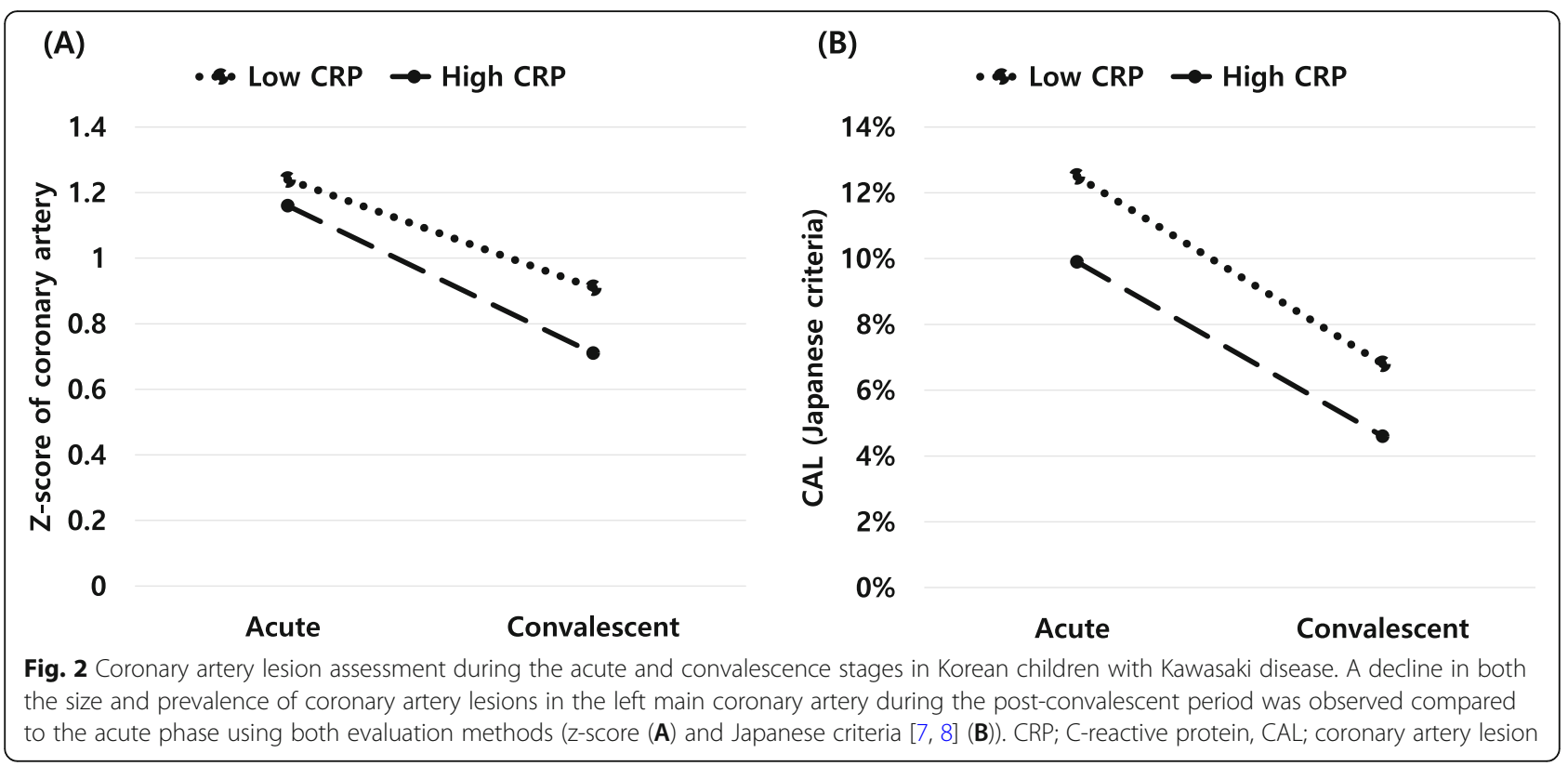

multivariable analysis. Regardless of the serum CRP level, if the duration of fever was longer, the risk of CAL was higher (odds ratio [OR], 1.112 [1.064-1.163]; $p<$ 0.001). Furthermore, IVIG non-responsiveness was associated with CAL development (OR, 2.617 [2.064-3.317]; $p<0.001)$.

In the high CRP group, the acute CAL risk was higher among non-responders to the second IVIG dose than among non-responders to the first IVIG dose (initial IVIG response: OR, 1.414 [1.223-1.634], $\mathrm{p}<0.001$; second IVIG response: OR, 2.884 [2.234-3.723], $\mathrm{p}<0.001)$. In the low CRP group, responsiveness to initial IVIG treatment was not associated with CAL occurrence. Increased CAL risk was shown only for non-responders to the second IVIG dose (initial IVIG response: OR, 1.147 [0.811-1.623], $p=0.438$; second IVIG response: OR, 2.283 [1.162-4.486], $p<0.017)$.

We performed a risk factor analysis for acute CAL development in the low CRP group. In the univariable analysis, the age at diagnosis, incomplete presentation of $\mathrm{KD}$, fever duration before treatment, and nonresponsiveness to secondary IVIG showed a statistically significant result (all $p<0.05$ ). In the multivariable analysis, all of these factors were also a risk factor for the occurrence of CAL (Table 3).

\section{Discussion}

In this retrospective analysis of the 9th Korean nationwide survey of $\mathrm{KD}$, the development of CAL was also found in patients with low serum CRP levels. In the low CRP group, CAL was observed in 18.3 and $12.5 \%$ of patients during the acute phase and 8.5 and $6.8 \%$ of patients after the convalescent period based on the $\mathrm{z}$-score and Japanese criteria, respectively.

CAL occurrence was higher in the low CRP group than in the high CRP group. Our study design did not allow us to identify or define the cause of this observation. However, patients in the low CRP group were younger at KD diagnosis and more often presented with incomplete $\mathrm{KD}$, which may be associated with a higher CAL occurrence than in patients in the high CRP group $[1,9,10]$. In analysis of incomplete $K D$, the occurrence of CAL was higher in low CRP group than that in high CRP group, but this pattern was not prominent in

Table 3 Risk factors for coronary artery lesion in patients with low C-reactive protein

\begin{tabular}{lllll}
\hline & Univariable analysis & & Multivariable analysis \\
\cline { 2 - 3 } & OR $(\mathbf{9 5 \% ~ C l )}$ & $\boldsymbol{p}$-value & OR (95\% Cl) & $0.930(0.873,0.991)$ \\
\hline Age at diagnosis & $0.953(0.901,1.008)$ & 0.090 & $2.142(1.672,2.745)$ & 0.025 \\
Incomplete KD & $2.188(1.713,2.794)$ & $<0.001$ & $1.101(1.045,1.159)$ & $<0.001$ \\
Fever, pretreatment & $1.092(1.041,1.145)$ & $<0.001$ & $3.235(1.550,6.753)$ & $<0.001$ \\
2nd IVIG unresponsiveness & $2.283(1.162,4.486)$ & 0.017 & 0.014 \\
\hline
\end{tabular}

During acute phase of KD

KD Kawasaki Disease, OR Odds ratio, IVIG Intravenous immunoglobulin, BCG Bacillus Calmette-Guérin 
analysis of complete KD. Therefore, it should be noted that CAL may occur even in incomplete patients with low CRP.

Although we did not describe it above, the patients have been also evaluated by ESR level (low ESR $<40$ $\mathrm{mm} / \mathrm{hr}$. $\leq$ high ESR) (supplementary Table 1). As the result of CRP, it was confirmed that CAL occurred even in the low ESR group. In other words, it was confirmed that CAL also occurred in patients with low initial inflammatory maker level.

In general, the risk assessment of coronary artery complications is evaluated based on IVIG responsiveness, and high serum CRP levels are regarded as a related factor for the non-responsiveness to IVIG $[11,12]$. The CRP value used to predict this non-responsiveness to IVIG is the initial CRP level, which reflects the inflammatory state prior to IVIG treatment. However, the initial serum CRP level alone may not be sufficient to predict complications. Nandi et al. showed a difference in the CRP and interleukin-6 (IL-6; a cytokine that stimulates inflammatory markers, including CRP) levels between IVIG responders and non-responders. They found that CRP and IL-6 levels were higher after IVIG treatment in IVIG non-responders than in responders; however, these levels were not significantly different before IVIG treatment [5]. High CRP levels after initial IVIG were also reported to be a risk factor for nonresponsiveness to additional IVIG treatment in refractory KD patients [13, 14]. Because the serum CRP levels after IVIG treatment were not investigated in this study, it is difficult to draw definitive conclusions, but we believe that the serum CRP level before IVIG treatment is insufficient to predict coronary artery complications.

In our study, the fever duration before treatment was not different between the low and high CRP groups, but there was a difference in responsiveness to IVIG treatment. In patients with low serum CRP levels, the rate of non-responsiveness to the first IVIG dose was 11.7\%, which was considerably lower than the overall nonresponse rate (18.3\%) to the first IVIG dose among all patients. In patients with low serum CRP levels, the response rate to the first IVIG dose was good, but coronary artery complications still occurred in some of these patients, which suggest that patients with low CRP levels may not be a homogeneous group. Some patients responded well to treatment without coronary complications, as would be expected based on their low CRP serum levels in others, coronary complications were found although they had appropriate treatment. One may hypothesize that a rise in CRP levels occurred after the initial test, but further research is required to test such a hypothesis.

In both groups, the presence of some principle symptoms was associated with a low risk of CAL. Notably, in the low CRP group, the presence of BCG site redness showed a low risk of CAL. Similar trends were identified in the high CRP group, with the presence of principle symptoms associated with a low risk of CAL. These results are in line with the findings of a previous study, which showed that coronary artery complications may be high due to the delayed diagnosis and treatment of patients with incomplete KD who have insufficient clinical symptoms to match the diagnostic criteria [1].

In this study, the characteristics of patients were similar to those of patients in the nationwide survey and other reported data [15-17]. However, our results should be interpreted within the limitations of this study. Because this analysis was performed retrospectively, patients lacking essential data required to interpret the results of this study were excluded $(n=6256)$; thus, 9131 patients who met the inclusion criteria were analyzed. Furthermore, serum CRP levels were collected just prior to initial IVIG treatment, but the exact day of sampling from fever onset was not investigated. The serum CRP level was associated with KD disease duration and it could not be linked with coronary artery outcome directly. In addition, since CRP after IVIG treatment has not been investigated, we cannot make any conclusions about the occurrence of CALs following CRP changes.

\section{Conclusions}

Coronary artery complications in KD occurred not only with high serum CRP levels $(\geq 3 \mathrm{mg} / \mathrm{dL}$ ) but also low serum CRP levels $(<3 \mathrm{mg} / \mathrm{dL})$ of before IVIG treatment. In addition, the CAL occurrence rate was higher in patients with low serum CRP levels than in patients with high serum CRP levels, which was associated with the higher CAL occurrence rate in incomplete KD. Therefore, we recommend monitoring the clinical course of KD carefully, regardless of the serum CRP level, and to note that coronary artery complications are not predictable based on serum CRP levels prior to IVIG treatment alone.

\section{Abbreviations}

BCG: Bacillus Calmette-Guerin; CAA: Coronary artery aneurysm; CAL: Coronary artery lesions; CRP: C-reactive protein; IVIG: Intravenous immunoglobulin; KD: Kawasaki Disease

\section{Supplementary Information}

The online version contains supplementary material available at https://doi. org/10.1186/s12969-021-00566-6.

\footnotetext{
Additional file 1. Coronary artery complications in children with Kawasaki disease (ESR).

Additional file 2. Coronary artery complications in children with Kawasaki disease (right coronary artery).

Additional file 3. Coronary artery complications in children with Kawasaki disease (complete vs. incomplete).
}

Additional file 4: Supplementary 4A. Coronary artery complications in children with Kawasaki disease (incomplete KD). Supplementary 4B Coronary artery complications in children with Kawasaki disease (complete KD). 


\section{Acknowledgements}

Not applicable.

\section{Authors' contributions}

GBK conceptualized and designed the study and reviewed and revised the manuscript. HSA conceptualized and designed the study, collected data, carried out the initial analyses, drafted the initial manuscript, and reviewed and revised the manuscript. MKS conceptualized and designed the study, carried out the initial analyses, and reviewed and revised the manuscript. SYL designed the data collection instruments, collected data, and reviewed and revised the manuscript. HWK conceptualized and designed the study, coordinated and supervised data collection, and reviewed and revised the manuscript. JWL collected data, coordinated and supervised data collection, and reviewed and revised the manuscript. EJB conceptualized and designed the study, coordinated and supervised data collection, and critically reviewed the manuscript for important intellectual content. All authors approved the final manuscript as submitted and agree to be accountable for all aspects of the work.

\section{Funding}

None declared.

\section{Availability of data and materials}

The datasets used and/or analysed during the current study are available from the corresponding author on reasonable request.

\section{Declarations}

\section{Ethics approval and consent to participate}

The study was approved by the Institutional Review Board of Seoul National University Hospital. The consent was waived because of the retrospective survey study nature (no. H-1710-109-895).

\section{Consent for publication}

Not applicable.

\section{Competing interests}

The authors have no conflict of interest relevant to this article to disclose.

Received: 19 November 2020 Accepted: 18 May 2021

Published online: 02 June 2021

\section{References}

1. McCrindle BW, Rowley AH, Newburger JW, Burns JC, Bolger AF, Gewitz M, et al. Diagnosis, treatment, and long-term management of Kawasaki disease: a scientific statement for health professionals from the American Heart Association. Circulation. 2017;135(17):e927-99. https://doi.org/10.1161/CIR. 0000000000000484

2. Kim GB. Reality of Kawasaki disease epidemiology. Kor J Pediatr. 2019;62(8): 292-6. https://doi.org/10.3345/kjp.2019.00157.

3. Koyanagi $H$, Yanagawa $H$, Nakamura Y, Yashiro M. Serum C-reactive protein levels in patients with Kawasaki disease: from the results of nation-wide surveys of Kawasaki disease in Japan. Acta Paediatr. 1997;86(6):613-9. https://doi.org/10.1111/j.1651-2227.1997.tb08944.x.

4. Chaudhary H, Nameirakpam J, Kumrah R, Pandiarajan V, Suri D, Rawat A, et al. Biomarkers for Kawasaki disease: clinical utility and the challenges ahead. Front Pediatr. 2019;7:242. https://doi.org/10.3389/fped.2019.00242.

5. Nandi A, Pal P, Basu S. A comparison of serum IL6 and CRP levels with respect to coronary changes and treatment response in Kawasaki disease patients: a prospective study. Rheumatol Int. 2019;39(10):1797-801. https:// doi.org/10.1007/s00296-019-04375-9.

6. Dallaire F, Dahdah N. New equations and a critical appraisal of coronary artery Z scores in healthy children. J Am Soc Echocardiogr. 2011;24(1):60-74 https://doi.org/10.1016/j.echo.2010.10.004.

7. Newburger JW, Takahashi M, Gerber MA, Gewitz MH, Tani LY, Burns JC, et al. Diagnosis, treatment, and long-term management of Kawasaki disease: a statement for health professionals from the committee on rheumatic fever, endocarditis, and Kawasaki disease, council on cardiovascular disease in the young. Am Heart Assoc Pediatr. 2004;114(6):1708-33. https://doi.org/10.1 542/peds.2004-2182
8. Kamiya T. Report of subcommittee on standardization of diagnostic criteria and reporting of coronary artery lesions in Kawasaki disease. Diagnostic criteria of cardiovascular lesions in Kawasaki diseasehttp://www.niph.go.jp/ wadai/mhlw/1984/s5906011.pdf; 1983. p. 1-10.

9. $\quad$ Singh S, Agarwal S, Bhattad S, Gupta A, Suri D, Rawat A, et al. Kawasaki disease in infants below 6 months: a clinical conundrum? Int J Rheum Dis. 2016;19(9):924-8. https://doi.org/10.1111/1756-185X.12854

10. Salgado AP, Ashouri N, Berry EK, Sun X, Jain S, Burns JC, et al. High risk of coronary artery aneurysms in infants younger than 6 months of age with Kawasaki disease. J Pediatr. 2017;185:112-116.e1.

11. Egami $K$, Muta $H$, Ishii $M$, Suda $K$, Sugahara $Y$, lemura $M$, et al. Prediction of resistance to intravenous immunoglobulin treatment in patients with Kawasaki disease. J Pediatr. 2006;149(2):237-40. https://doi.org/10.1016/j. jpeds.2006.03.050

12. Sano T, Kurotobi S, Matsuzaki K, Yamamoto T, Maki I, Miki K, et al. Prediction of non-responsiveness to standard high-dose gamma-globulin therapy in patients with acute Kawasaki disease before starting initial treatment. Eur J Pediatr. 2007:166(2):131-7

13. Iwashima S, Kimura M, Ishikawa T, Ohzeki T. Importance of C-reactive protein level in predicting non-response to additional intravenous immunoglobulin treatment in children with Kawasaki disease: a retrospective study. Clin Drug Investig. 2011:31(3):191-9. https://doi.org/1 0.2165/11538910-000000000-00000

14. Nakagama $Y$, Inuzuka R, Hayashi T, Shindo T, Hirata $Y$, Shimizu N, et al. Fever pattern and C-reactive protein predict response to rescue therapy in Kawasaki disease. Pediatr Int. 2016:58(3):180-4. https://doi.org/10.1111/ ped.12762.

15. Kim GB, Park S, Eun LY, Han JW, Lee SY, Yoon KL, et al. Epidemiology and clinical features of Kawasaki disease in South Korea, 2012-2014. Pediatr Infect Dis J. 2017;36(5):482-5. https://doi.org/10.1097/INF.0000000000001474.

16. Kim GB, Yu JJ, Yoon KL, Jeong SI, Song YH, Han JW, et al. Medium- or higher-dose acetylsalicylic acid for acute Kawasaki disease and patient outcomes. J Pediatr. 2017:184:125-129.e121.

17. Makino N, Nakamura Y, Yashiro M, Kosami K, Matsubara Y, Ae R, et al. Nationwide epidemiologic survey of Kawasaki disease in Japan, 2015-2016. Pediatr Int. 2019;61(4):397-403. https://doi.org/10.1111/ped.13809.

\section{Publisher's Note}

Springer Nature remains neutral with regard to jurisdictional claims in published maps and institutional affiliations.
Ready to submit your research? Choose BMC and benefit from:

- fast, convenient online submission

- thorough peer review by experienced researchers in your field

- rapid publication on acceptance

- support for research data, including large and complex data types

- gold Open Access which fosters wider collaboration and increased citations

- maximum visibility for your research: over $100 \mathrm{M}$ website views per year

At BMC, research is always in progress.

Learn more biomedcentral.com/submissions 